\title{
Composition and Morphology of Nanocrystals in Urines of Lithogenic Patients and Healthy Persons
}

\author{
Bao-Song Gui, ${ }^{1}$ Rong Xie, ${ }^{2}$ Xiu-Qiong Yao, ${ }^{2}$ Mei-Ru Li, ${ }^{1}$ and Jian-Ming Ouyang ${ }^{2}$ \\ ${ }^{1}$ Department of Nephrology, The Second Hospital of Xi' an Jiaotong University, Xi'an, 710004, China \\ ${ }^{2}$ Institute of Biomineralization and Lithiasis Research, Jinan University, Guangzhou 510632, China \\ Correspondence should be addressed to Bao-Song Gui, guibsdoctor@sina.com and Jian-Ming Ouyang, toyjm@jnu.edu.cn
}

Received 13 June 2009; Accepted 1 September 2009

Recommended by Virtudes Moreno

The composition and morphology of nanocrystals in urines of healthy persons and lithogenic patients were comparatively investigated by means of X-ray diffraction (XRD) and transmission electron microscopy (TEM). It was shown that the main composition of urinary nanocrystals in healthy persons were calcium oxalate dihydrate (COD), uric acid, and ammonium magnesium phosphate (struvite). However, the main compositions of urinary nanocrystals in lithogenic patients were struvite, $\beta$-tricalcium phosphate, uric acid, COD, and calcium oxalate monohydrate (COM). According to the XRD data, the size of nanocrystals was calculated to be $23 \sim 72 \mathrm{~nm}$ in healthy urine and $12 \sim 118 \mathrm{~nm}$ in lithogenic urine by Scherer formula. TEM results showed that the nanocrystals in healthy urine were dispersive and uniform with a mean size of about $38 \mathrm{~nm}$. In contrast, the nanocrystals in lithogenic urine were much aggregated with a mean size of about $55 \mathrm{~nm}$. The results in this work indicated that the urinary stone formation may be prevented by diminishing the aggregation and the size differentiation of urinary nanocrystals by physical or chemical methods.

Copyright (C) 2009 Bao-Song Gui et al. This is an open access article distributed under the Creative Commons Attribution License, which permits unrestricted use, distribution, and reproduction in any medium, provided the original work is properly cited.

\section{Introduction}

Urolithiasis, which occurs in $1 \sim 20 \%$ in Asia, $5 \sim 9 \%$ in Europe, and approximately $13 \%$ in North America, is a worldwide common and frequently occurring disease $[1,2]$. Especially, it has high incidence in adult men among $20 \sim 40$ years old who have large amount of exercise. The main components of urinary stones include calcium oxalate, calcium phosphate, uric acid, magnesium ammonium phosphate (struvite), and cystines. Approximately $80 \%$ of stones are calcic in which calcium oxalate is the main component [2-5].

The first step of urinary stone formation is the nucleation of particles in supersaturated urine. Then the formed nuclei (generally less than $10 \mathrm{~nm}$ ) grow or/and aggregate to a pathological size (several tens micron). After these crystallites are retained on the urinary tract (free-particle theory) or fixed by the urinary tract organization (fixed-particle theory), urinary stones ultimately formed [6].

According to the chemical properties, urinary stone can be classified into acidic stones (such as uric acid, cystine), alkaline stones (such as struvite), and neutral stones (such as calcium oxalate, calcium phosphate). However, clinical practices neither can be predicted before stone formation nor can be individually treated by taking different medicine and different treatment methods for different types of urinary stones. Thus it results in a low treatment ratio. Thereby, if the occurrence of urinary stones can be predicted or the type of stones can be estimated before treatment by the determination of urinary composition and urinary nanocrystals, it will provide evidence for a suitable remedy and personalized treatment in clinic.

XRD has advantages of reliability in qualitative analysis and accuracy in quantitative analysis. It operates simply and has a high sensitivity. Based on XRD diffraction data, the multicomponents in a sample can be measured simultaneously, and the approximate size of the nanoparticles can also be calculated by means of Scherer formula. For example, Chen et al. [7] had calculated the size of nanosilver (Ag) to be 7-22 nm, and Satyanarayana et al. [8] had calculated the size of nanocuprous oxide $\left(\mathrm{Cu}_{2} \mathrm{O}\right)$ to be $11 \mathrm{~nm}$ by Scherer formula. Transmission electron microscopy (TEM), with larger amplification and high resolution, is commonly 
TABLE 1: Urinary stone risk profile in lithogenic patients and in normal subjects.

\begin{tabular}{lcr}
\hline Urine parameter & Lithogenic patients $(n=16)$ & Normal subjects $(n=17)$ \\
\hline Volume, $\mathrm{L}$ & $1721 \pm 429$ & $1202 \pm 354$ \\
$\mathrm{pH}$ & $6.32 \pm 0.35$ & $6.02 \pm 0.32$ \\
Calcium, $\mathrm{mmol} / \mathrm{L}$ & $5.51 \pm 1.32$ & $5.71 \pm 2.11$ \\
Oxalate, $\mathrm{mmol} / \mathrm{L}$ & $0.53 \pm 0.09$ & $0.29 \pm 0.05$ \\
Citrate, $\mathrm{mmol} / \mathrm{L}$ & $1.71 \pm 0.94$ & $2.32 \pm 0.85$ \\
Phosphorus, $\mathrm{mmol} / \mathrm{L}$ & $15.3 \pm 5.8$ & $16.1 \pm 4.7$ \\
\hline
\end{tabular}

used in the observation of nanomaterials. The examination of urinary nanocrystals by means of TEM can help us to understand the relationship between these nanocrystals and formation of various types of urinary stones.

Based on the discussed above, the composition, size, morphology, and aggregation of the nanocrystals of less than $100 \mathrm{~nm}$ in healthy urines and in lithogenic urines are comparatively investigated by XRD and TEM. We hope it would provide enlightenment on diagnosing and treating urinary stone.

\section{Experimental Details}

2.1. Materials. Anhydrous alcohol and sodium azide were reagent-grade chemicals. All the glasswares were cleaned with the ultrapure water from the Millipore-Q system; the resistance was $18.2 \mathrm{M} \Omega \mathrm{cm}$. The fresh morning urine samples were collected from both patients who had urinary stones and healthy persons with no prior history of urinary stones.

2.2. Apparatus. TEM was carried out by PHILIPS TECNAI10 transmission electron microscope at an operating voltage of $100 \mathrm{kV}$. X-ray diffraction (XRD) results were recorded on a D/max 2400

X-ray diffractometer (Rigaku, Japan) used graphite monochromator, Ni-filtered $\mathrm{CuK} \alpha$ radiation $(\lambda=$ $0.15406 \mathrm{~nm})$, and a scanning rate of $0.02^{\circ} \mathrm{s}^{-1}$ at $40 \mathrm{kV}$, $30 \mathrm{~mA}$. The divergence and scattering slit was $1^{\circ}$ for the range $5^{\circ}<2 \theta<60^{\circ}$. Urinary stones and urinary crystals were identified according [9]. Magnesium ammonium phosphate monohydrate $\left(\mathrm{MgNH}_{4} \mathrm{PO}_{4} \cdot \mathrm{H}_{2} \mathrm{O}\right)$ and hexahydrate $\left(\mathrm{MgNH}_{4} \mathrm{PO}_{4} \cdot 6 \mathrm{H}_{2} \mathrm{O}\right.$, struvite $)$ were compared with ASTM card number 20-0663 and 77-2303, respectively. Octacalcium phosphate $\left(\mathrm{Ca}_{8} \mathrm{H}_{2}\left(\mathrm{PO}_{4}\right)_{6} \cdot 5 \mathrm{H}_{2} \mathrm{O}\right)$, calcium phosphate $\left(\mathrm{Ca}_{3}\left(\mathrm{PO}_{4}\right)_{2}, \mathrm{CaP}\right)$, and hydroxylapatite (HAP) were compared with the number 44-0778, 32-176, and 09-0432, respectively. Uric acid (UA), calcium oxalate monohydrate (COM), and dihydrate (COD) were compared with the number 09-0432, 20-231, and 17-541, respectively.

\subsection{Clinical Data and Test Method.}

2.3.1. Clinical Data. The participants in the study included sixteen lithogenic patients ( 9 men and 7 women) with a mean age of 44.7 years (23 70 years old) and seventeen random selected healthy human ( 8 men and 9 women) with

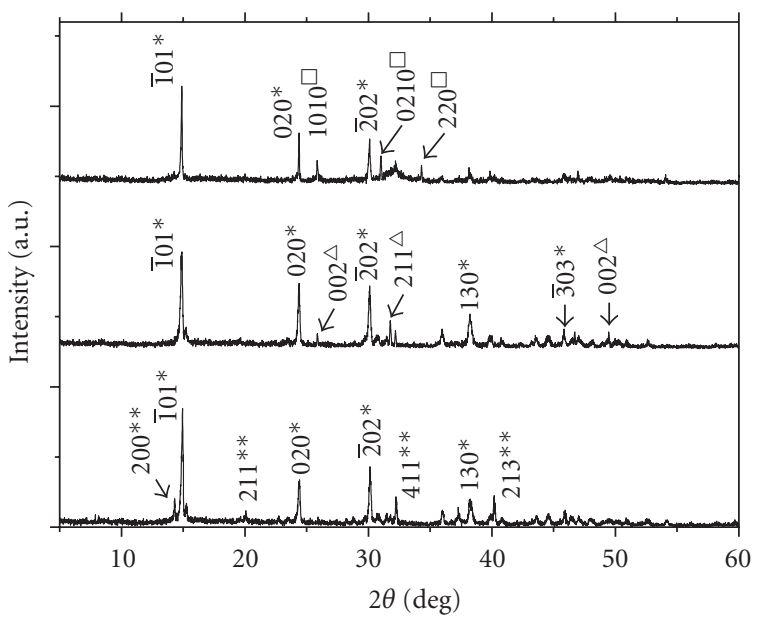

FIGURE 1: XRD patterns of three representative urinary stones $(*$ : $\mathrm{COM}, * *$ : COD, $\triangle$ : HAP, $\left.\square: \mathrm{Ca}_{3}\left(\mathrm{PO}_{4}\right)_{2}\right)$.

no prior history of urinary stone with a mean age of 38.6 years (22 53 years old). The urinary stones were collected after surgery, cleared by double distilled water, and put in a no dust incubator about $50^{\circ} \mathrm{C}$ to make dry, then grinded into powder by agate mortar for XRD and FT-IR characterization. The results showed that the main compositions of these stones were $\mathrm{CaOxa}$ or $\mathrm{CaOxa}-\mathrm{CaP}$. The XRD patterns of three representative urinary stones were shown in Figure 1. The fresh morning urine from the patients with $\mathrm{CaOxa}$ stone or $\mathrm{CaOxa-CaP}$ stone was collected from 06:00 to 08:00 AM. without being submitted to special diets. Peoples who provided urine samples did not eat any food from 9:00 PM. last night to acquisition time of their urine samples. Table 1 showed the urinary stone risk profile in urine of lithogenic patients and normal subjects.

2.3.2. Test Method. After the fresh morning urine was collected, $2 \%$ (weight/volume ratio) $\mathrm{NaN}_{3}$ solution (urine : $\mathrm{NaN}_{3}=100: 1$ in volume) was immediately added into the urine as antiseptic. Then the urine was added anhydrous alcohol (urine: anhydrous alcohol $=3: 2$ in volume) and was stood for half hour to make the urinary protein denaturation. The cell debris and the denatured protein precipitations were filtered out using a microporous membrane with the pore size of $1.2 \mu \mathrm{m}$. It was shown that the filtration with a $1.2 \mu \mathrm{m}$ microporous membrane had significant influence on the 
TABLE 2: Main diffraction peaks ( $d$ value) and corresponding crystal faces of urinary nanocrystals.

\begin{tabular}{lcc}
\hline Nanocrystal in urine & $d$ value (crystal plane) & ASTM card [9] \\
\hline $\mathrm{NH}_{4} \mathrm{MgPO}_{4} \cdot \mathrm{H}_{2} \mathrm{O}$ & $8.79(010), 2.80(121), 4.73(110), 4.20(011), 3.24(012)$ & $36-1491$ \\
$\mathrm{NH}_{4} \mathrm{MgPO}_{4} \cdot 6 \mathrm{H}_{2} \mathrm{O}$ & $5.60(020), 3.66(121), 3.29(130), 2.80(040), 2.01(151)$ & $15-762$ \\
$\mathrm{C}_{5} \mathrm{H}_{4} \mathrm{~N}_{4} \mathrm{O}_{3}$ & $4.91(210), 3.86(\overline{2} 11), 3.19(021), 3.10(\overline{1} 21)$ & $31-1982$ \\
$\beta-\mathrm{Ca}_{3}\left(\mathrm{PO}_{4}\right)_{2}$ & $4.06(024), 4.00(116), 2.88(217), 2.20(404), 1.81(210)$ & $9-169$ \\
$\mathrm{CaC}_{2} \mathrm{O}_{4} \cdot \mathrm{H}_{2} \mathrm{O}(\mathrm{COM})$ & $5.93(\overline{10} 01), 3.65(020), 2.97(202), 2.84(121), 1.98(\overline{3} 03)$ & $20-231$ \\
$\mathrm{CaC}_{2} \mathrm{O}_{4} \cdot 2 \mathrm{H}_{2} \mathrm{O}(\mathrm{COD})$ & $6.18(200), 4.42(211), 3.91(310), 2.78(411), 2.34(501)$, & $17-541$ \\
& $2.24(213), 2.00(323), 1.62(730)$ & \\
\hline
\end{tabular}

particles larger than $400 \mathrm{~nm}$ and exerted little influence on the small particles with the size less than $100 \mathrm{~nm}$ in the two kinds of urines.

The filtrate was added on a copper mesh for TEM detection and on clean glass tablet for XRD characterization simultaneously. For the former, the copper mesh was put in a desiccators, and for the latter, the glass tablet was put in a no dust incubatorat at $50^{\circ} \mathrm{C}$ for 4 hours to make urine evaporation.

\section{Results and Discussion}

3.1. Differentiation of Components of Urinary Nanocrystals in Lithogenic Urine and in Healthy Urine. XRD was used to investigate the composition of urinary nanocrystals of 16 lithogenic patients and 17 healthy persons. Figures 2 and 3 showed the representative XRD patterns of the urinary nanocrystals in three healthy persons and in three lithogenic patients, respectively. Compared with the standard diagrams (see Table 2) [9], the main peaks in Figure 2(a) were assigned to the (110) crystal plane of $\mathrm{MgNH}_{4} \mathrm{PO}_{4} \cdot \mathrm{H}_{2} \mathrm{O}$, the (021) plane of uric acid (411), (501), and (730) planes of calcium oxalate dihydrate (COD). The main peaks in Figure 2(b) were assigned to the $(\overline{2} 11)$ plane of uric acid, the (121) plane of $\mathrm{MgNH}_{4} \mathrm{PO}_{4} \cdot 6 \mathrm{H}_{2} \mathrm{O}$, and the (411) and (323) planes of COD crystals. The main peaks in Figure 2(c) were assigned to the (310), (411), and (323) planes of COD crystal. That is, all the three urinary nanocrystals in healthy persons contained COD crystals.

In the three XRD patterns of urinary nanocrystals of lithogenic patients (see Figure 3), the main peaks in Figure 3(a) were, respectively, assigned to the (024) and (404) crystal planes of $\beta-\mathrm{Ca}_{3}\left(\mathrm{PO}_{4}\right)_{2}$ and the (040) and (151) planes of $\mathrm{MgNH}_{4} \mathrm{PO}_{4} \cdot 6 \mathrm{H}_{2} \mathrm{O}$. The main peaks in Figure 3(b) were assigned to the (130) and (040) planes of $\mathrm{MgNH}_{4} \mathrm{PO}_{4} \cdot 6 \mathrm{H}_{2} \mathrm{O}$, the (121) plane of COM, and the (210) plane of $\beta-\mathrm{Ca}_{3}\left(\mathrm{PO}_{4}\right)_{2}$, respectively. In Figure 3(c) the main peaks were, respectively, assigned to the ( $(\overline{2} 11)$ and (021) planes of uric acid, and the (411) and (323) planes of COD crystals

All the XRD results showed that the urinary nanocrystals were mainly COD, uric acid and magnesium ammonium phosphate in healthy urine (see Figure 2) and were mainly magnesium ammonium phosphate, $\beta$-tricalcium phosphate, $\mathrm{COD}$, and COM in lithogenic urine (see Figure 3).

It could be seen that the peak intensities of struvite crystals in urine of lithogenic patients (see Figure 3(a)) were stronger than those in urine of healthy persons (see Figures 2(a)-2(b)). It was attributed to that the concentration of citrate in health urine $(2.32 \pm 0.85 \mathrm{mmol} / \mathrm{L})$ was higher than that in lithogenic urine $(1.71 \pm 0.94 \mathrm{mmol} / \mathrm{L})$ as shown in Table 1 and as reported by Biyani et al. [10]. Citrate could form complexes with phosphoric acid or phosphate in urine, therefore inhibited struvite precipitation [11].

It could also be seen that the peak intensities of (411) and (323) crystal planes of COD crystals in urine of healthy persons (see Figures 2(a)-2(c)) were stronger than those in urine of lithogenic patient (see Figure 3(c)). Since the diffraction peak intensity was positively related with the number of crystals, it indicated that the amount of COD crystals in healthy urine was more than that in lithogenic urine.

The differentiation of COD crystals in the two kinds of urine was attributed to the difference of urinary inhibitors. These urinary inhibitors could inhibit the formation of COM crystals and induce the growth of COD crystals [12-14]. One kind of these inhibitors was small molecule substance such as citrate, glutamic acid, pyrophosphate, magnesium, and the other kind was the urinary macromolecules such as glycosaminoglycans (GAGs), uromucoid, prothrombin fragment F1 (UPTF1), Tamm-Horsfall protein, nephrocalcin $(\mathrm{NC})$, osteopontin $(\mathrm{OPN})$, and polyribonucleotide [10, $15,16]$. These substances, especially the urinary macromolecules, had much negative charges and were inclined to be the nucleated nidus for urinary stone such as $\mathrm{CaOxa}$ stone $[17,18]$. For the bipyramidal COD crystals, there were only high-density charged locate at the two vertexes in which the $\mathrm{Oxa}^{2-}$ ions were outstanding and negatively charged. However, the surfaces of COM crystals were positively charged [19]. So the negatively charged urinary macromolecules preferentially combined with the face of COM crystals, which is positively charged [20-22] and blocked the growth sites on the surface of COM. It increased the negative value of Zeta potential on the surface of COM crystals and led to a stronger repellent action among the nanocrystals in urine. Thus, the nucleation and growth of COM crystals in healthy urine were inhibited. However, in urine of lithogenic patients, either the concentration of macromolecules was less or their activity was lower. For example, the concentration of GAGs in urine of healthy human was about $8.80 \pm$ $1.92 \mathrm{mg} / \mathrm{L}$; however, it decreased to about $6.08 \pm 1.39 \mathrm{mg} / \mathrm{L}$ in lithogenic urine. Therefore, the interaction between the urinary macromolecules and nanocrystals was weaker in urine of lithogenic patients. Thus less COD crystals were 


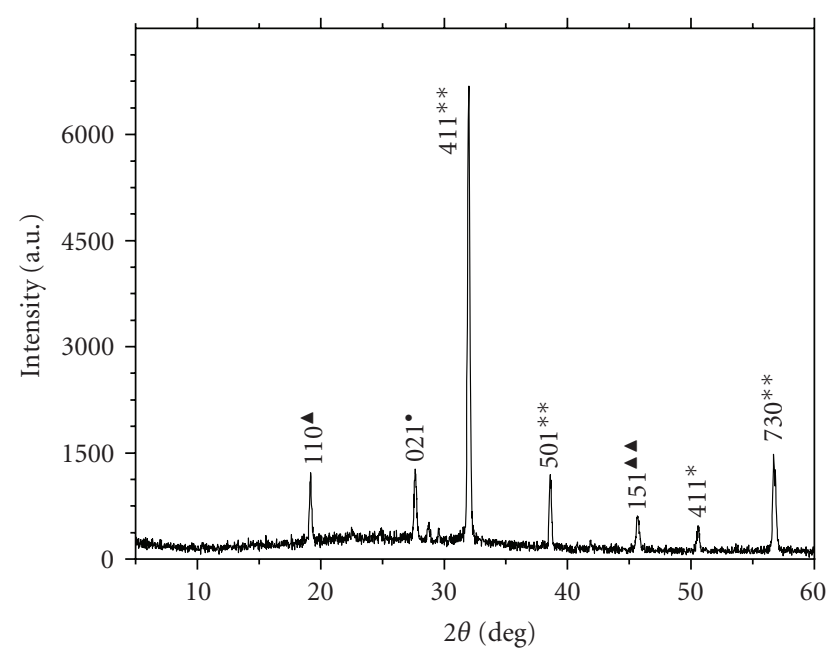

(a)

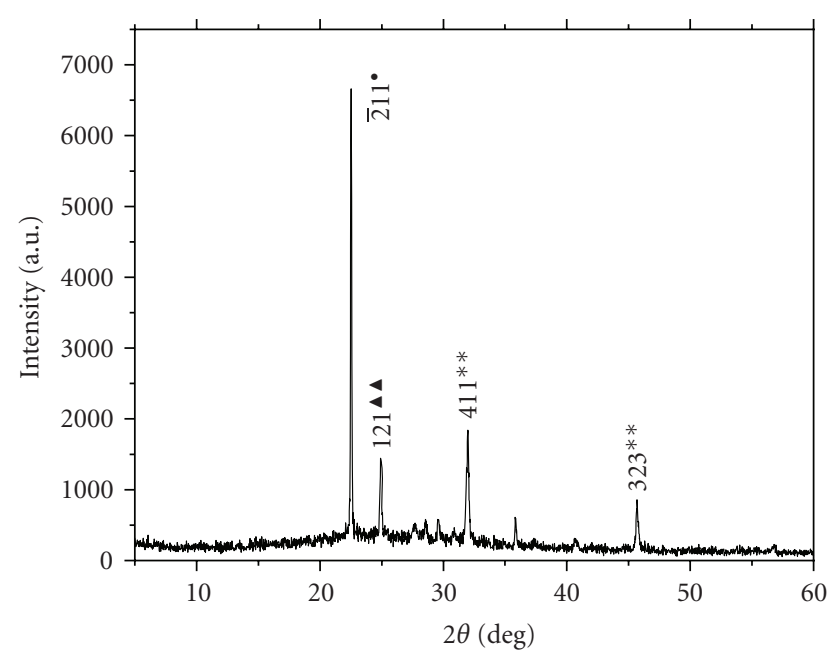

(b)

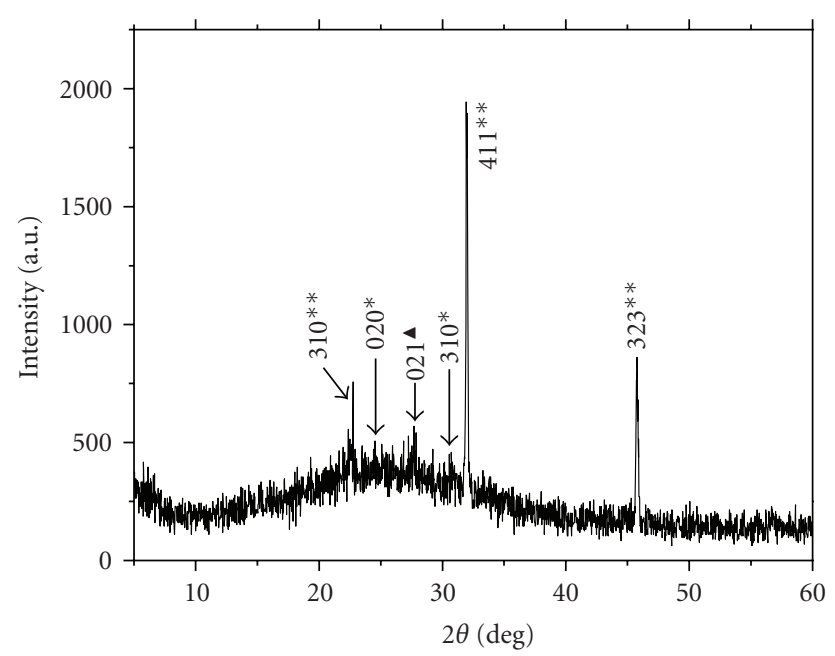

(c)

FIGURE 2: XRD patterns of typical urinary crystals of three health persons $(\mathrm{H} 1, \mathrm{H} 2, \mathrm{H} 3)$. ( $*$ : $\mathrm{COM}, * *: \mathrm{COD}, \bullet$ : uric acid, $\boldsymbol{\Delta}$ : $\left.\mathrm{MgNH}_{4} \mathrm{PO}_{4} \cdot \mathrm{H}_{2} \mathrm{O}, \boldsymbol{\Delta} \boldsymbol{\Delta}: \mathrm{MgNH}_{4} \mathrm{PO}_{4} \cdot 6 \mathrm{H}_{2} \mathrm{O}\right)$.

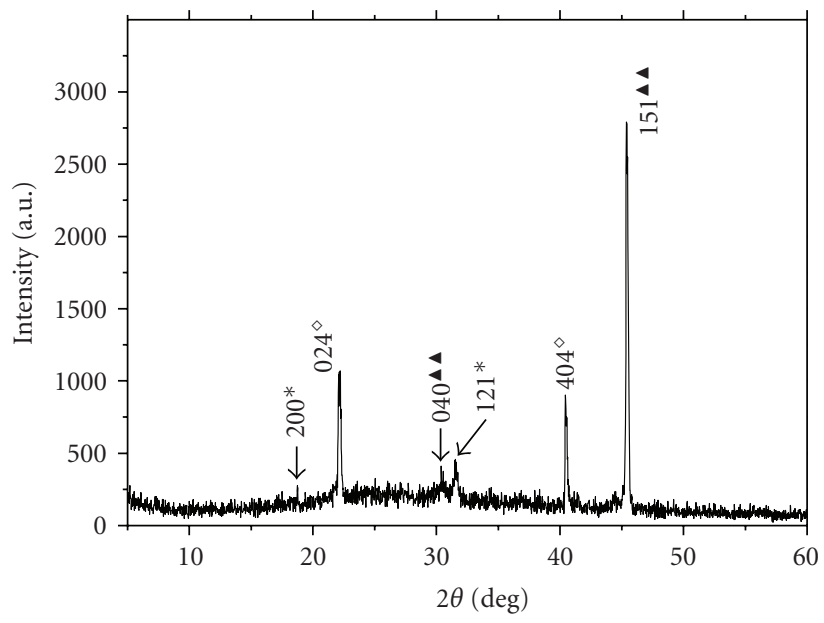

(a)

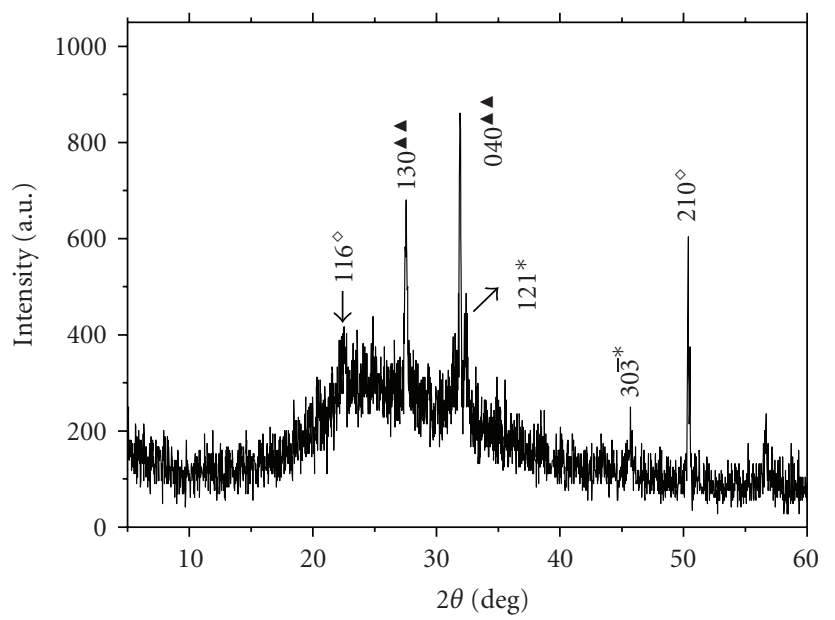

(b)

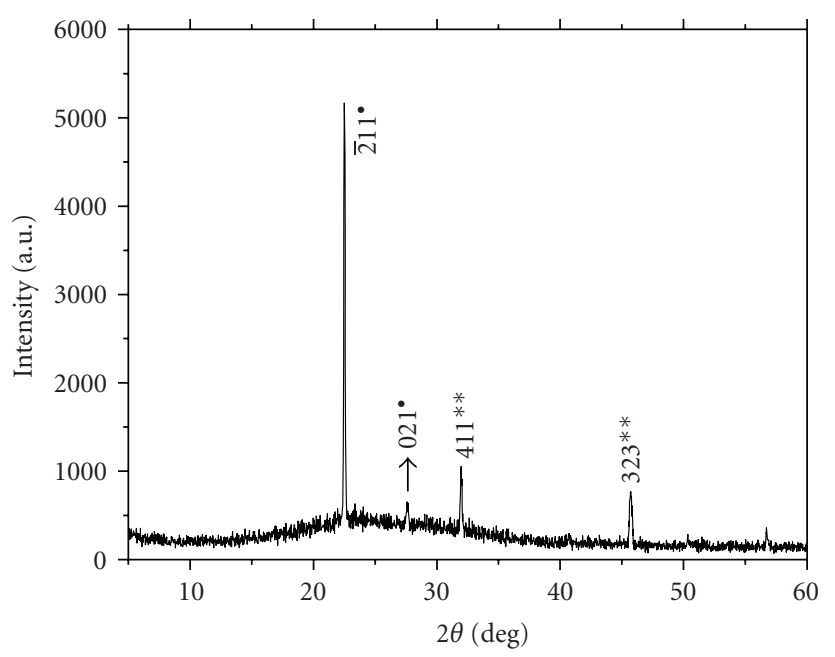

(c)

FIGURE 3: XRD patterns of typical urinary crystals of three lithogenic patients (L1, L2, L3). (*: COM, **: COD, •: uric acid, $\left.\boldsymbol{\Delta} \mathbf{\Delta}: \mathrm{MgNH}_{4} \mathrm{PO}_{4} \cdot 6 \mathrm{H}_{2} \mathrm{O},: \beta-\mathrm{Ca}_{3}\left(\mathrm{PO}_{4}\right)_{2}\right)$. 


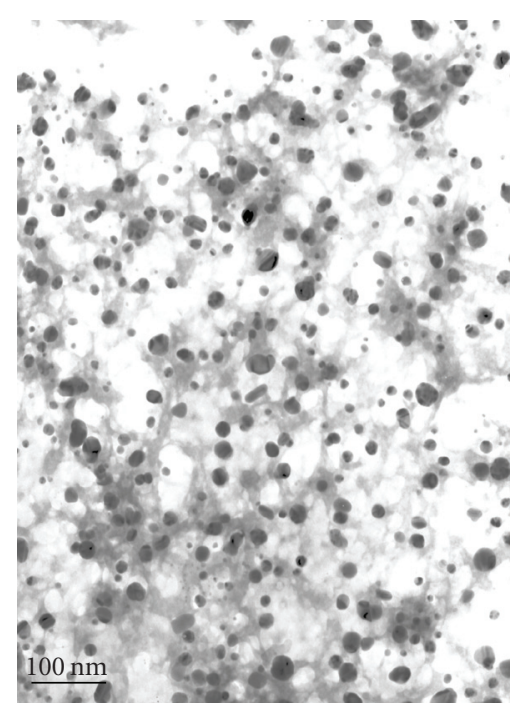

(a)

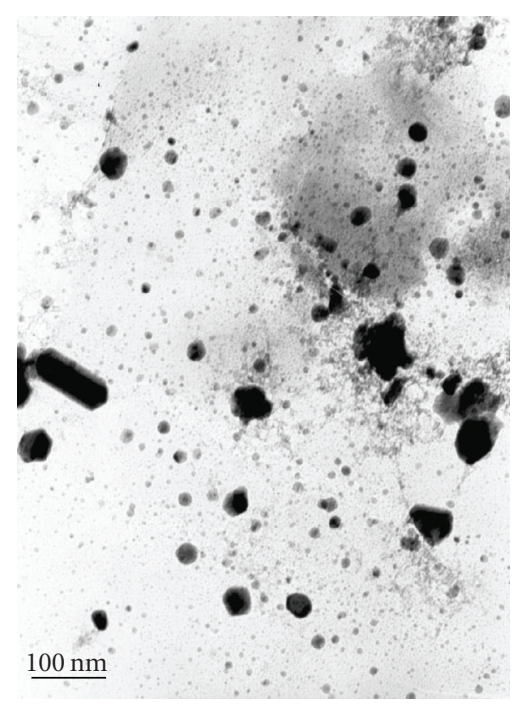

(c)

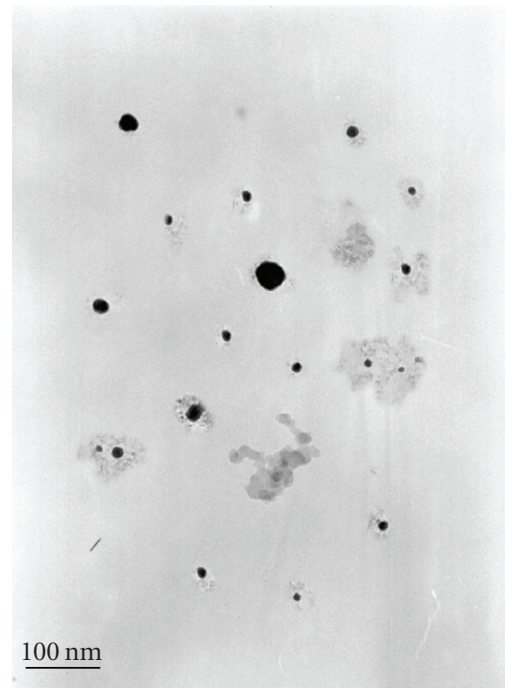

(b)

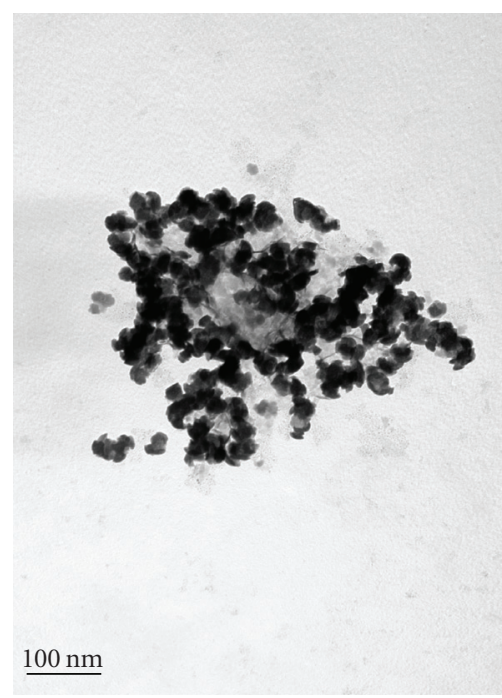

(d)

FIgURE 4: TEM images of typical urinary nanocrystals of two health persons (a), (b) and two lithogenic patients (c), (d). The bar is 100 nm.

induced. That is, calcium oxalate mainly precipitated as COM crystals in the urine of lithogenic patients. It made the intensity of diffraction peaks of COD crystals in healthy urine generally be stronger than that in lithogenic urine.

\subsection{Differentiation of Morphology and Aggregation of Urinary} Nanocrystals in Lithogenic Urine and in Healthy Urine. Figure 4 showed the TEM images of representative urinary nanocrystals of healthy persons and lithogenic patients. The urinary nanocrystals of healthy persons were well dispersed and uniform with a size distribution between $15 \mathrm{~nm}$ and 60 $\mathrm{nm}$ (see Figures 4(a), 4(b)). In contrast, the nanocrystals of lithogenic patients were not uniform with a size distribution ranging from $10 \mathrm{~nm}$ to more than $100 \mathrm{~nm}$ (see Figures 4(c), $4(\mathrm{~d})$ ). In addition, more aggregated nanocrystals were found in lithogenic urine.
Based on the XRD diffraction data, not only could the components of samples be measured, but also the approximate size of the nanoparticles could be calculated using Scherer formula [7, 8, 23] as shown in (1):

$$
L=\frac{K \lambda}{\cos \theta \cdot \Delta(2 \theta)},
$$

where $L$ was the size of the nanoparticles, $\mathrm{K}$ is constant and is dependent on crystallite shape (0.89), $\lambda$ was the $\mathrm{X}$-ray wavelength $(\lambda=1.5418 \AA$ in this experiment), $\Delta(2 \theta)$ was the radian value of fwhm (full width at half-max), and $\theta$ was the Bragg angle. For example, in Figure 2(a), the strongest characteristic diffraction peak of COD crystals was the (411) face with a $d$ value of $0.279 \mathrm{~nm}$, the corresponding $2 \theta=$ $32.00^{\circ}$ and $\theta=16.00^{\circ}$. The maximal intensity of this peak was 6689.2 , so the height at half-max was 3344.6 , and the 
TABLE 3: Sizes of urinary nanocrystals in three healthy persons $(\mathrm{H})$ and in three lithogenic patients (L) calculated using scherer formula $(\mathrm{nm})$.

\begin{tabular}{|c|c|c|c|c|c|c|}
\hline Urine nanocrystals & $\mathrm{H} 1$ & $\mathrm{H} 2$ & $\mathrm{H} 3$ & L1 & $\mathrm{L} 2$ & L3 \\
\hline $\mathrm{COD}$ & $41 \sim 47$ & $37 \sim 49$ & $45 \sim 51$ & - & - & $36 \sim 45$ \\
\hline struvite & 32 & 40 & - & - & - & - \\
\hline uric acid & 23 & 72 & - & - & - & $27 \sim 65$ \\
\hline$\beta-\mathrm{Ca}_{3}\left(\mathrm{PO}_{4}\right)_{2}$ & 一 & 一 & - & $29 \sim 45$ & 118 & 一 \\
\hline struvite & 一 & 一 & - & 51 & $12 \sim 39$ & 一 \\
\hline
\end{tabular}

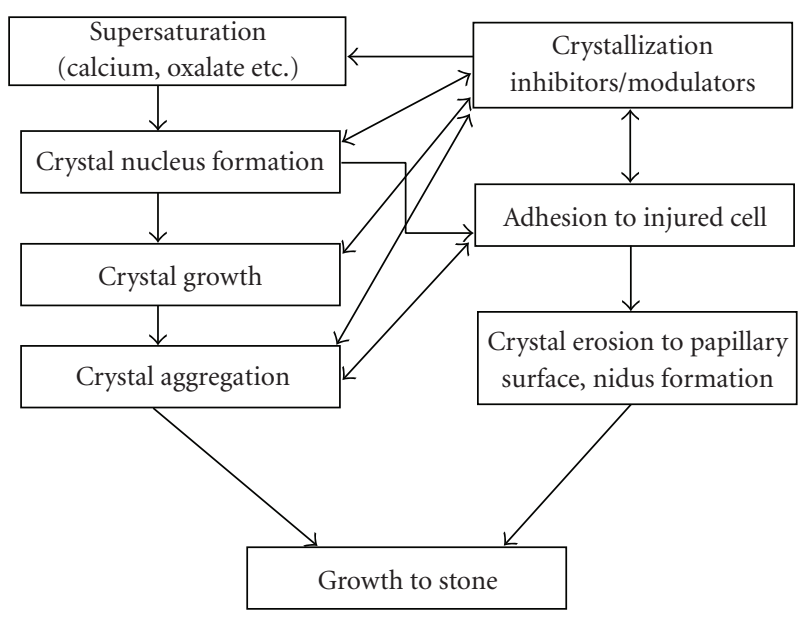

FIGURE 5: Schematic diagram of urinary stone formation.

corresponding $2 \theta$ values at the two points of half-max were $32.09^{\circ}$ and $31.86^{\circ}$, respectively. That was $\triangle(2 \theta)\left(32.09^{\circ}-\right.$ $\left.31.86^{\circ}\right) \cdot \pi / 180^{\circ}$. By substituting these values into (1), we could figure out that the size of COD nanocrystals $L$ (COD) was $41 \mathrm{~nm}$. By means of the same method, we could also figure out the size of the other nanocrystals in healthy urine. For example, for the sample $\mathrm{H} 1$ in Figure 2(a), $L$ $\left(\mathrm{MgNH}_{4} \mathrm{PO}_{4} \cdot \mathrm{H}_{2} \mathrm{O}\right)=32 \mathrm{~nm}(110$ face $), L$ (uric acid $)=23$ $\mathrm{nm}$ (021 face), and $L(C O D)=41 \sim 47 \mathrm{~nm}$ ((411), (501), and (730) faces). For the sample H2 in Figure 2(b), L(COD) $=37 \sim 49 \mathrm{~nm}((411)$ and (323) faces), $L$ (uric acid) $=72$ $\mathrm{nm}(\overline{2} 11$ face $), L$ (struvite) $=40 \mathrm{~nm}$ (121 face). For the sample $\mathrm{H} 3$ (Figure 2(c)), L(COD) $=45 \sim 51 \mathrm{~nm}$ ((310), (411), and (323) faces) (see Table 3).

For the urinary nanocrystals in lithogenic urine sample L1 (Figure 3(a)), it could be calculated that the size of nano$\beta-\mathrm{Ca}_{3}\left(\mathrm{PO}_{4}\right)_{2}\left(L\left(\beta-\mathrm{Ca}_{3}\left(\mathrm{PO}_{4}\right)_{2}\right)\right)$ was $29 \sim 45 \mathrm{~nm}((024)$ and (404) faces); $L\left(\mathrm{MgNH}_{4} \mathrm{PO}_{4} \cdot \mathrm{H}_{2} \mathrm{O}\right)=51 \mathrm{~nm}((040)$ and (151) faces). For sample L2 (Figure 3(b)), $L\left(\beta-\mathrm{Ca}_{3}\left(\mathrm{PO}_{4}\right)_{2}\right)=118$ $\mathrm{nm}((210)$ face $)$, and $L$ (struvite $)=12 \sim 39 \mathrm{~nm}((130)$ and (040) faces). For sample L3 (Figure 3(c)), $L$ (uric acid) $=27 \sim$ $65 \mathrm{~nm}((\overline{2} 11)$ and $(021)$ faces $)$, and $L(C O D)=36 \sim 45 \mathrm{~nm}$ ((411) and (323) faces).

That is, the size of nanocrystals in the healthy persons urine ranged from $23 \mathrm{~nm}$ to $72 \mathrm{~nm}$, and those in lithogenic patients urine ranged from $12 \mathrm{~nm}$ to $118 \mathrm{~nm}$. The results obtained from Scherer formula were nearly consistent with those observed from the TEM method.
Since there was a different ratio of volume to surface area for the particles with different size, it led to the difference in their solubility. According to the mechanism of Ostwald ripening [24], when solid particles were dispersed in their own saturated solution, there was a tendency that the small-size particles be dissolved and the solute be deposited subsequently on the large-size particles. Therefore, the uneven distribution of nanoparticles in lithogenic urine made the small-size crystals disappeared and the largesize crystals grew; thus these urine samples were unstable. However, the nanoparticles in healthy urine were uniform. It led to a weak interaction and a small difference of the surface free energy between particles; thus the driving force for these nanoparticles to aggregate diminished and finally these urine samples were stable.

Although the formation of urinary stones correlated with many factors, it necessarily went through the following processes: the formation of crystal nucleus in urine, the growth and/or aggregation of the crystallites, and the adhesion of crystallites on renal epithelial cell, as shown in Figure 5. According to the calculation results of crystal growth rate and flow rate of urine through tubule lumen, a single crystallite could not block the tubule lumen badly when it passed the nephron. Only after the urine crystallites had combined with other substances such as the cell debris in urine, the aggregated crystallites were formed, then the larger size of crystals could block the nephron, and finally stone formed [25].

Since the growth, aggregation and the final formation of urinary stones were apparently affected by the components, size, and uniformity of urinary nanocrystals, therefore, urinary stone formation may be prevented by diminishing the size differentiation and the aggregation of nanocrystals in urine through physical or chemical methods. The investigatation about the existing state of urinary nanocrystals and the detection of the components and properties of nanocrystals in urine would be beneficial to find out the connection between stone formation and urinary nanocrystals and then to provide evidences for a suitable remedy and personalized treatment to urolithiasis in clinic.

\section{Conclusion}

The composition and morphology of nanocrystals in urines of healthy persons and lithogenic patients were comparatively investigated by means of XRD and TEM. XRD patterns showed that the urinary nanocrystals mainly were COD, uric acid, and magnesium ammonium phosphate in 
healthy persons; but mainly were magnesium ammonium phosphate, $\beta$-tricalcium phosphate, COD, and COM in lithogenic patients. Especially the amount of COD crystals in healthy urine was much more than that in lithogenic urine. Based on the XRD diffraction data, the size of urinary nanocrystals was figured out to be $23 \sim 72 \mathrm{~nm}$ in healthy urine and about $12 \sim 118 \mathrm{~nm}$ in lithogenic patients, respectively, by means of Scherer formula. TEM results showed that the nanocrystals in healthy urine were dispersive and uniform with an average size of about $38 \mathrm{~nm}$. In contrast, the nanocrystals in lithogenic urine were much aggregated with an average size of about $55 \mathrm{~nm}$. It was consistent with the results calculated from XRD data. The results showed that the urinary stone formation may be prevented by diminishing the size differentiation and the aggregation of nanocrystals in urine through physical or chemical methods.

\section{Acknowledgments}

This research work was granted by the Natural Science Foundation of China (30672103) and the Key Project of Guangdong Province (2009B030801236). The authors are grateful to Dr. Kuang Li and Dr. Liang Wei-Bo of the first Affiliated Hospital of Medical College of Jinan University for providing the urine samples of lithogenic patients.

\section{References}

[1] X. X. Sheng, T. S. Jung, A. W. Jeffrey, and D. W. Michael, "Adhesion at calcium oxalate crystal surfaces and the effect of urinary constituents," Proceedings of the National Academy of Sciences, vol. 102, no. 2, pp. 267-272, 2005.

[2] M. Tsujihata, "Mechanism of calcium oxalate renal stone formation and renal tubular cell injury," International Journal of Urology, vol. 15, no. 2, pp. 115-120, 2008.

[3] G. Felix, C. B. Antonia, R. Margarita, M. Vicente, and C. Antonio, "Simple classification of renal calculi closely related to their micromorphology and etiology," Clinica Chimica Acta, vol. 322, pp. 29-36, 2002.

[4] W. Ochmanski, J. Kmiecik, and W. SuLowicz, "Analysis of chemical composition of urinary stones," International Urology and Nephrology, vol. 31, no. 6, pp. 743-750, 1999.

[5] A. N. Kofina and P. G. Koutsoukos, "Spontaneous precipitation of struvite from synthetic wastewater solutions," Crystal Growth and Design, vol. 5, no. 2, pp. 489-496, 2005.

[6] N. Laube, B. Mohr, and A. Hesse, "Laser-probe-based investigation of the evolution of particle size distributions of calcium oxalate particles formed in artificial urines," Journal of Crystal Growth, vol. 233, no. 1-2, pp. 367-374, 2001.

[7] Q. Chen, L. Yue, F. Y. Xie, et al., "Preferential facet of nanocrystalline silver embedded in polyethylene oxide nanocomposite and its antibiotic behaviors," Journal of Physical Chemistry C, vol. 112, no. 27, pp. 10004-10007, 2008.

[8] I. Prakash, P. Muralidharan, N. Nallamuthu, M. Venkateswarlu, and N. Satyanarayana, "Preparation and characterization of nanocrystal size cuprous oxide," Materials Research Bulletin, vol. 42, pp. 1619-1624, 2007.

[9] M. King, W. F. McClure, L. C. Andrews, and M. A. Holomery, "Powder diffraction file alphabetical index, inorganic phases/organic phases," Tech. Rep., International Center for Diffraction Data, Park Lane, Pa, USA, 1992.
[10] D. R. Basavaraj, C. S. Biyani, A. J. Browning, and J. J. Cartledge, "The role of urinary kidney stone inhibitors and promoters in the pathogenesis of calcium containing renal stones," $E A U$ EBU Update Series, vol. 5, no. 3, pp. 126-136, 2007.

[11] A. N. Kofina, K. D. Demadis, and P. G. Koutsoukos, "The effect of citrate and phosphocitrate on struvite spontaneous precipitation," Crystal Growth and Design, vol. 7, no. 12, pp. 2705-2712, 2007.

[12] T. S. Jung, X. X. Sheng, C. K. Choi, W. S. Kim, J. A. Wesson, and M. D. Ward, "Probing crystallization of calcium oxalate monohydrate and the role of macromolecule additives with in situ atomic force microscopy," Langmuir, vol. 20, no. 20, pp. 8587-8596, 2004.

[13] S. W. Guo, M. D. Ward, and J. A. Wesson, "Direct visualization of calcium oxalate monohydrate crystallization and dissolution with atomic force microscopy and the role of polymeric additives," Langmuir, vol. 18, no. 11, pp. 4284-4291, 2002.

[14] B. Akin, M. Öner, Y. Bayram, and K. D. Demadis, "Effects of carboxylate-modified, "green" inulin biopolymers on the crystal growth of calcium oxalate," Crystal Growth and Design, vol. 8, no. 6, pp. 1997-2005, 2008.

[15] J.-M. Ouyang, "Effects of temperature on growth and aggregation of calcium oxalate in presence of various carboxylic acids in silica gel systems," Materials Science and Engineering $C$, vol. 26, no. 4, pp. 679-682, 2006.

[16] L. J. Wang, X. Y. Guan, R. K. Tang, et al., "Phosphorylation of osteopontin is required for inhibition of calcium oxalate crystallization," The Journal of Physical Chemistry B, vol. 112, no. 30, pp. 9151-9157, 2008.

[17] J. G. Yu, H. Tang, B. Cheng, and X. J. Zhao, "Morphological control of calcium oxalate particles in the presence of poly(styrene-alt-maleic acid)," Journal of Solid State Chemistry, vol. 177, no. 10, pp. 3368-3373, 2004.

[18] J. M. Ouyang, L. Duan, and B. Tieke, "Effects of carboxyl acids on the crystal growth of calcium oxalate nanocrystals in lecithin-water liposome systems," Langmuir, vol. 19, pp. 89808985, 2003.

[19] J. M. Ouyang, S. P. Deng, J. P. Zhong, B. Tieke, and S. H. Yu, "Crystallization of calcium oxalate monohydrate at dipalmitoylphosphatidyl-choline monolayers in the presence of chondroitin sulfate A," Journal of Crystal Growth, vol. 270, pp. 646-654, 2004.

[20] D. B. Zhang, L. M. Qi, J. M. Ma, and H. M. Cheng, "Morphological control of calcium oxalate dihydrate by a double-hydrophilic block copolymer," Chemistry of Materials, vol. 14, no. 6, pp. 2450-2457, 2002.

[21] B. Hess, Y. Nakagawa, and F. L. Coe, "Inhibition of calcium oxalate monohydrate crystal aggregation by urine proteins," American Journal of Physiology, vol. 257, no. 1, pp. 99-106, 1989.

[22] N. Mandel, "Crystal-membrane interaction in kidney stone disease," Journal of the American Society of Nephrology, vol. 5, pp. 37-45, 1994.

[23] L. H. Xin, R. M. Zhou, B. G. Ekoko, and O. F. Adeleke, "Synthesis of silver nano-particles by EB irradiation," Journal of Radiation Research and Radiation Processing, vol. 22, no. 2, pp. 69-72, 2004.

[24] J. W. Mullin, Ed., Crystallization, Butterworth Heinemann, Boston, Mass, USA, 3rd edition, 2000.

[25] C. F. Verkoelen, B. G. Van Der Boom, A. B. Houtsmuller, F. H. Schröder, and J. C. Romijn, "Increased calcium oxalate monohydrate crystal binding to injured renal tubular epithelial cells in culture," American Journal of Physiology Renal Physiology, vol. 274, pp. 958-964, 1998. 


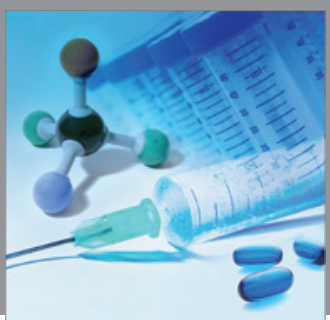

International Journal of

Medicinal Chemistry

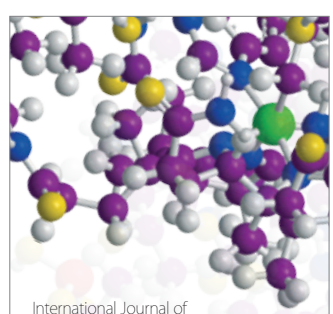

Carbohydrate Chemistry

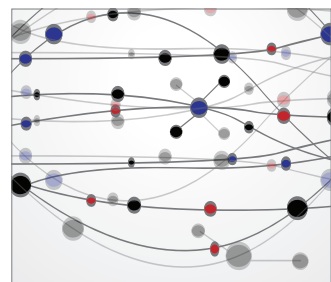

The Scientific World Journal
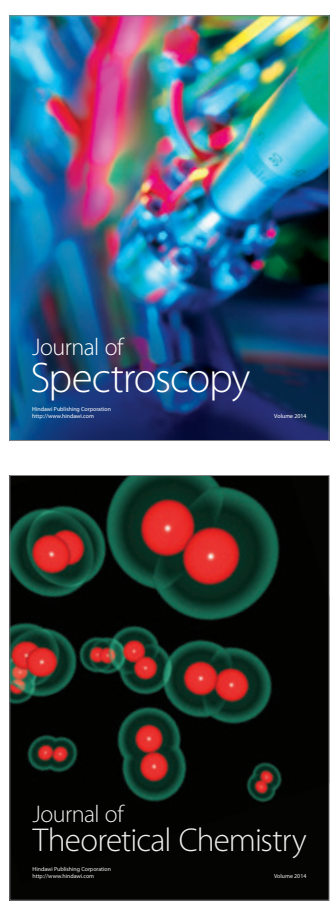
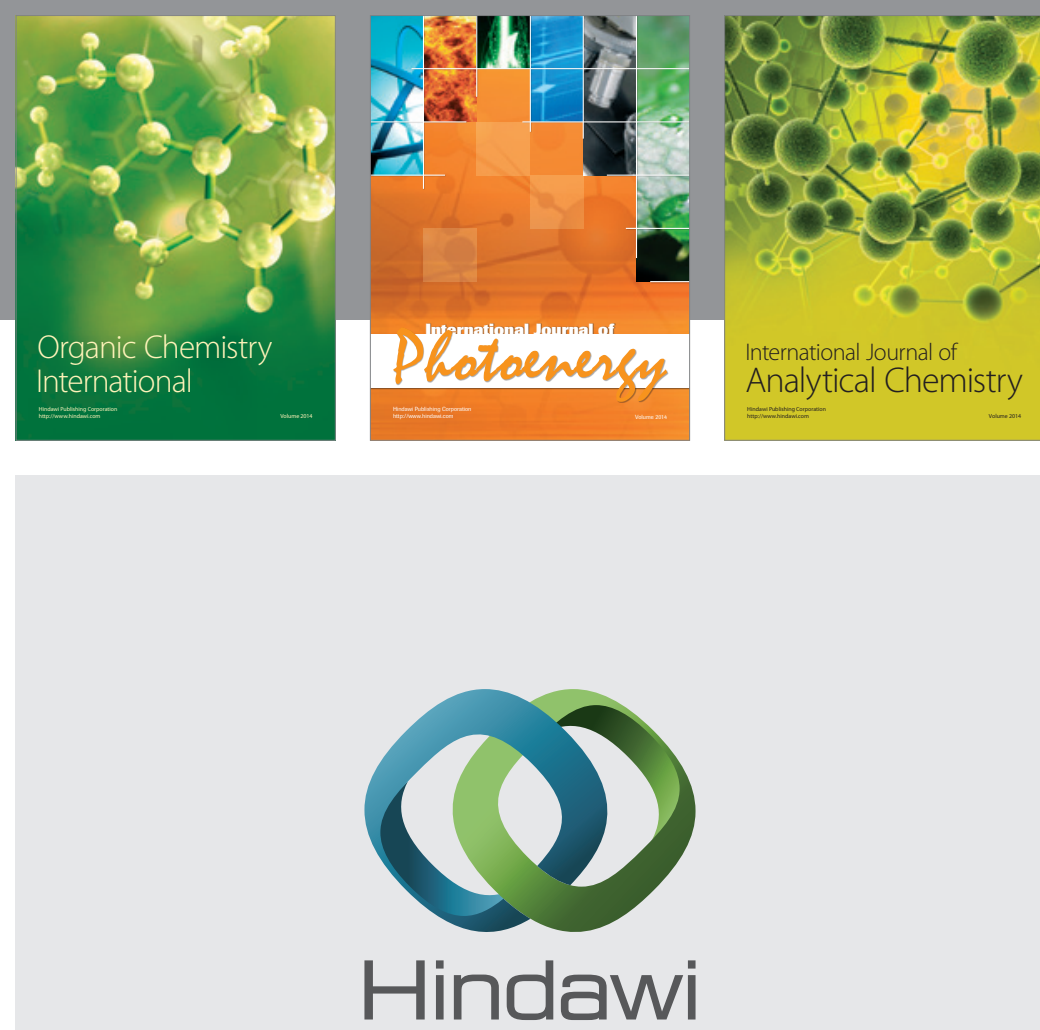

Submit your manuscripts at

http://www.hindawi.com
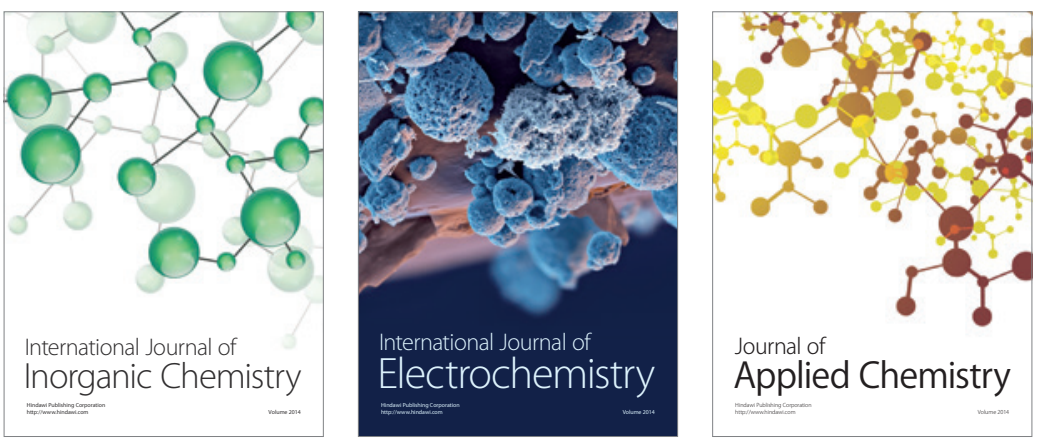

Journal of

Applied Chemistry
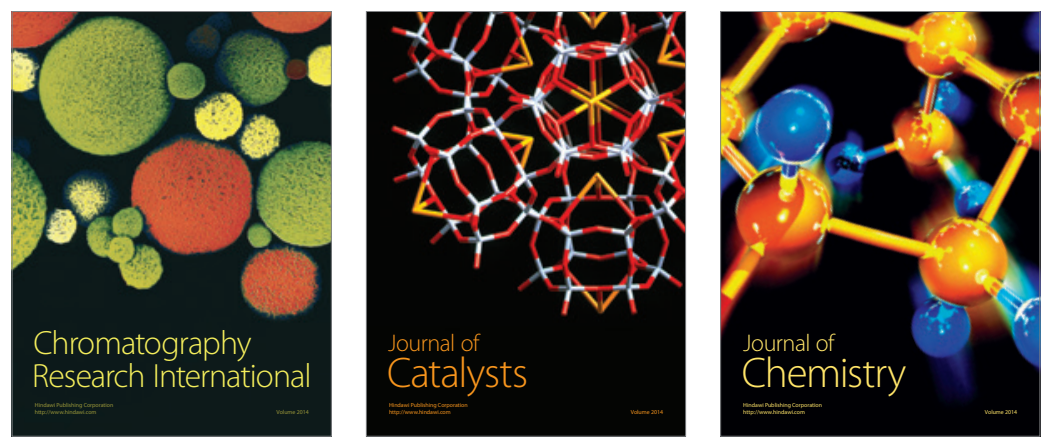
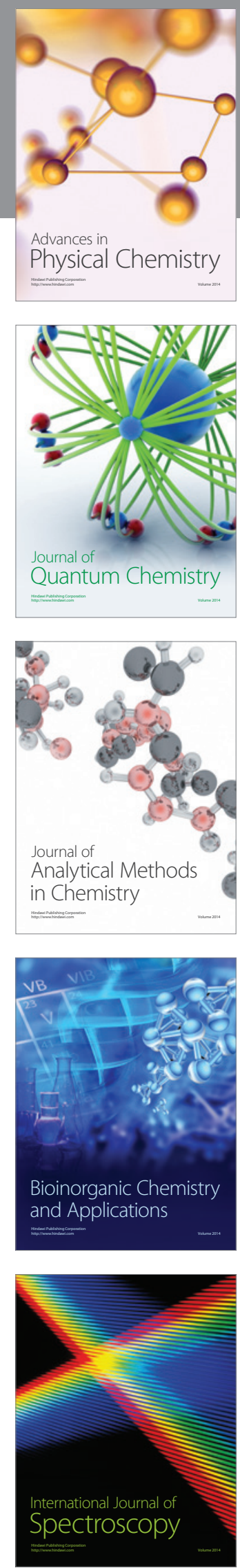